\title{
ROYAL ACADEMY OF MEDICINE IN IRELAND SECTION OF ANAESTHESIA
}

\author{
Residents' Paper Presentation, Thursday, 14th December, 1989.
}

\section{MEDIASTINAL AND SUBCUTANEOUS EMPHYSEMA SUBSEQUENT TO PERFORATION OF AN INTRATHORACIC STOMACH}

C. Cooney, J. Malik, U. Callaghan, G. Fitzpatrick.

Department of Anaesthesia, Meath Hospital, Dublin.

An 80 year old female presented with the clinical features of a perforated intra-abdominal viscus. Following rapid sequence of anaesthesia the larynx was visual ised but an endotracheal tube could not be passed below the level of the cricoid. The registrar called the consultant and proceeded to manually ventilate the patient with $100 \%$ oxygen via the face mask. Gross subcutaneous emphysema of the neck and upper trunk then developed and the patient became cyanosed. Despite the inconclusive chest $\mathrm{X}$-ray bilateral chest drains were inserted. The patient resumed spontaneous respiration and her condition improved.

Following re-inroduction of anaesthesia a 6.0 endotracheal tube was passed. Bronchoscopy and laryngoscopy revealed no evidence of trauma. There was no difficulty with ventilation via the tube anaesthesia being maintained with oxygen, nitrous oxide, enflurane and pancuronium. Subcutaneous emphysema increased initially after intubation, thereafter anaesthesia proceeded uneventfully and laparotomy revealed a large hiatus and perforation of the intrathoracic stomach.

It is likely that manual ventilation via the mask forced gas through the perforation into the mediastinum. The increase in subcutaneous emphysema after intubation may have been due to diffusion of nitrous oxide. This case highlights the previously unreported anaesthetic implications of perforation in an intrathoracic stomach.

\section{ORGANOPHOSPHATE OVERDOSE, AN INTERMEDIATE SYNDROME AND USE OF GLYCOPYRROLATE}

D. McCoy.

Department of Anaesthesia, Beaumont Hospital, Dublin.

A 21 year old male presented 2 hours after ingestion of $1000 \mathrm{mls}$ of Porect with a cholinergic crisis. On admission he was conscious but drowsy with pinpoint pupils, marked muscle fasciculations and bronchorrhoea. Blood gases showed moderate hypoxia, metabolic acidosis and respiratory alkalosis. Arterial blood pressure was 120/ $70 \mathrm{~mm} / \mathrm{Kg}$ and heart rate $120 / \mathrm{min}$. His respiratory status deteriorated over the following 12 hours and he required intubation and ventilatory support.

Pharmacological treatment included Pralidoxime, with Atropine and Glycopyrrolate combination in an effort to control cholinergic symptoms while avoiding the toxic manifestations of large doses of Atropine.

Literature review to date has not revealed reports of the use of Glycopyrrolate or Atropine - Glycopyrrolate combination in the treatment of organophosphate overdose.

Mechanical ventilation was required for 13 days and the patient was discharged on day 15 with no neurological sequelae.

Classically a cholinergic crisis develops within minutes to 2 hours following ingestion. The timing of respiratory deterioration and few muscarinic symptoms suggested the recently described intermediate syndrome.

\section{GAS GANGRENE - ANAESTHETIC MANAGEMENT OF 2 PATIENTS}

C. Redahan, H. Gallagher.

Department of Anaesthesia, University College Hospital, Galway.

The anaesthetic management of two patients with gas gangrene is described. The first patient was admitted with a limp and a right hip swelling. Her condition deteriorated dramatically with signs consistent of gas gangrene, septic shock and ARDs. Exploratory laparotomy revealed an appendicular abscess. She had debridement down to muscle from the right subcostal to the right knee extending posteriorly in the right flank. She had several sessions in the decompression chamber with hyperbaric oxygen. Though her gas gangrene improved, she died 12 days post admission of multiorgan failure.

The second patient was involved in a road traffic accident and sustained a compound and comminuted fracture to his femur and a vascular injury to the middle third of the superficial femoral artery. An extenal fixator was applied to the bony injury and a synthetic graft for repair of the vascular one. The synthetic graft became infected. Fasciotomies were performed for a swollen thigh and the anterior compartment of the right leg was found to be necrotic. He was given six sessions in the decompression chamber and, as no improvement occurred, his right leg was amputated.

Management of patients in decompression chambers requires alterations to the ventilator, blood pressure sphygmomonometers and intravenous infusions.

Discussion of cases will include anaesthetic management of patients in the decompression chamber.

\section{THE USE OF EPIDURAL BLOOD PATCH IN THE TREATMENT OF POST MYELOGRAM HEADACHE}

J. Owens.

Department of Anaesthesia, Beaumont Hosital, Dublin.

Headache is the most common complication of dural puncture and has been reported in $76 \%$ of patients undergoing myelography. Though there are significant differences in the incidence of sideeffects between the various contrast media, studies do suggest that most side-effects are related to the dural puncture and not to the contrast agent. The logical treatment for ongoing headache after myelogram should then be Epidural Blood Patch.

Five patients with severe postural headache and meningism after myelography are described. All had failed to respond to conservative management and were unable to mobilize. Four were still occupying a hospital bed four days after myelography. All were apyrexial and not clinically toxic. Each had $15 \mathrm{mls}$ of autologous blood, drawn under aseptic conditions, injected into the lumbar epidural space.

Four patients were pain-free at $1 \mathrm{hr}$ and discharged home at $4 \mathrm{hrs}$. One patient was considerably improved at $1 \mathrm{hr}$, pain-free at $8 \mathrm{hrs}$ and discharged at $16 \mathrm{hrs}$. Five patients exhibiting considerable iatrogenic morbidity, occupying hospital beds, with increased risk of thromboembolism and subdural haematoma were quickly and safely "cured". Epidural-Blood Patch is advocated as the definitive treatment of severe refractory myelogram headache, as originally suggested by Bridebaugh in 1977. 


\section{SEVERE GUILLAIN-BARRE SYNDROME IN PREGNANCY}

M. G. Coughlan, D. Phelan, P. McKenna.

Departments of Anaesthesia and Obstetrics/Gynaecology, Mater Misericordiae Hospital, Dublin.

A 35 year old gravida 2, para 1, woman at 18 weeks gestation was admitted to hospital with a three day history of pain and increasing weakness of both upper and lower limbs. One week earlier she had suffered an influenza-like illness. Cerebrospinal fluid and nerve conduction studies correlated with the diagnosis of Guillane-Barre syndrome (GBS). Progressive respiratory failure required tracheal intubation. Subsequently tracheostomy allowed tracheobronchial toilet and mechanical ventilation for eight weeks. Specific therapy for GBS consisted of a total of 15 litres of plasma exchange. Failure to absorb enteral nutrition necessitated intravenous nutrition for 21 days. Further support included anticoagulation, analgesia provided by epidural opiates and vigorous surveillance for sepsis. Premature labour occurred at 36 weeks gestation and caesarean section was carried out because of a premature breech presentation. In conclusion the successful management, with unique features, of a case of severe GBS in pregnancy is described.

\section{MALIGNANT HYPERPYREXIA - A MOST UNUSUAL CASE}

\section{Lynch, K. McGrath, G. Morris.}

Department of Anaesthesia, Beaumont Hospital, Dublin.

A 56 year old male was admitted with acute appendicitis. He had a family history of malignant hyperpyrexia $(\mathrm{MH})$, previous surgery included an arthroscopy and coronary artery bypass.

After dantrolene $2.5 \mathrm{mg} / \mathrm{Kg} \mathrm{IV}$ and preoxygenation, anaesthesia was induced with midazolam $10 \mathrm{mg}$, fentany $150 \mu \mathrm{g} / \mathrm{Kg}$ and atracurium $50 \mathrm{mg}$. He was intubated and ventilated with $100 \%$ oxygen via a dedicated vapour free ventilator and anaesthetic machine.

There were no per-operative problems and an acutely inflamed, non perforated appendix was removed. Post operatively the patient was transferred to I.C.U. for ventilation and monitoring. Five hours later, he began to breathe spontaneously and an MH crisis rapidly followed. Treatment was commenced immediately with dantrolene IV, active cooling with cold fluids etc, increased $\mathrm{F}_{1} \mathrm{O}_{2}$ and sodium bicarbonate. He responded well to therapy and his temperature was gradually controlled. He was extubated the following day and made an excellent recovery. He was discharged home after seven days and consistently refused referral for muscle biopsy.

We believe this represents a most unusual case of an MH crisis. The patient was pretreated with dantrolene and a trigger-free anaesthetic regime used. A search of the literature reveals no similar cases.

\section{A CASE OF THYROID STORM PRESENTING IN THE POST- OPERATTVE PERIOD}

H. O'Mahony, D. Phelan.

Department of Anaesthesia, Mater Misericordiae Hospital, Dublin.

Introduction. Thyroid crisis is rare. A lady who presented with the syndrome immediately post-operatively demonstrates the need for awareness and a new therapeutic approach.

Case Report. A 35 year old female was commenced on carbimazole for Grave's Disease. She became hypothyroid 3 months before an incidental hysterectomy requiring cessation of therapy and replacement thyroxine. She was clinically euthyroid and had a normal thyroxine pre-operatively.
Surgery and anaesthesia were uneventful. Three hours later she became anxious and centrally cyanosed and demonstrated a tachycardia, lid lag, tremor and an audible bruit.

Thyrotoxicosis was recognised and supportive therapy in intensive care was commenced. Specific therapy consisted of propylthiouacil, hydrocortisone and iodine $65 \mathrm{mg}$. Beta blockade was attempted with intravenous propranolol $(45 \mathrm{mg}$ ) but the patient developed bronchospasm which necessitated change to metoprolol with good effect.

She was discharged enthyroid from the I.C.U. within 36 hours.

A thyroxine level taken during the crisis later came back as greater than $210 \mathrm{nMol} / \mathrm{s}$.

Discussion. Specific therapy is aimed at the preventing of peripheral tri-iodothyronine production and at stopping the release of preformed thyroxine.

This case highlights the importance of early diagnosis and aggressive therapeutic management. It also shows the important role metoprolol has to play in the management of thyrotoxicosis.

\section{References}

1. Thyroid Storm and its Management. Mackin, J. F. et al. New England Journal of Medicine, December 26th, 1974.

2. Thyroid Storm presenting as Coma. Howton, J. C. Annals of Emergency Medicine, April, 1988 (4), 343-5.

3. The Selective Beta-1 Blocking agent Metoprolol compared wth antithyroid drug and thyroxine as pre-operative treatment of patients with hyperthyroidism. Adlerberthet al. Annals of Surgery, 1987, Feb.: 205 (2), 182-8.

\section{EMERGENCY SURGERY POST MYOCARDIAL INFARCTION}

P. Benson, V. Hannon.

Department of Anaesthesia, St. Vincent's Hospital, Dublin.

A 59 year old man presented for scheduled emergency gastrectomy three weeks post acute myocardial infarction (M.I.) because of persistent blood loss secondary to gastric cancer. Relevant history included :

1. Third M.I. in five years, on this occasion complicated by cardiac arrest, persistent tachydysthythmia and ventricular ectopy.

2. Severe long standing chronic obstructive pulmonary disease with superimposed steroid dependent asthma. Pulmonary function tests were V.C. $58 \%$, FEVI $34 \%$ and PEFR $41 \%$ of normal, respectively.

E.C.G. lead II and CM5, arterial, venous and pulmonary capillary wedge pressures were monitored pre-, per-, and post-operatively. Pre-op renal dopamine and nitroglycerine infusions were started. Lignocaine was infused to treat the arrhythmia and to obtund the bronchial response to intubation and anaesthesia. High dose fentanyl $(30 \mathrm{mcg} / \mathrm{kg}$ ) technique was employed. In I.C.U. post-op, the patient was ventilated electively, dopamine and GTN were weaned over 12 hours and lignocaine infusion continued for 24 hours. Serial PCWF, LVSWI and C.O. measurement was performed post-op. Patient was transferred to ward day 4 post-op.

Anaesthesia and surgery post M.I. has a recognised high mortality/ morbidity (Goldman, Caldera et al, 1977.NEJM 197,845-850). This patient has a Goldman classification III (complication rate 14\%). His status was further complicated by COPD/Asthma. The good outcome re-affirmed the recommendation regarding aggressive monitoring in patients with recent M.I. The lignocaine infusion allowed control over two separate pathologies and its judicious use in this type of patient is to be recommended. 